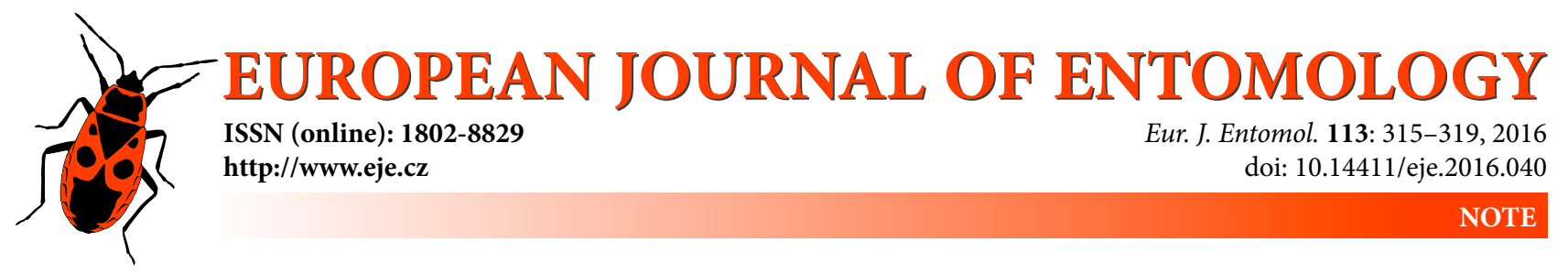

\title{
Capsazepine affects thermal preferences of the American cockroach (Blattodea: Blattidae)
}

\author{
JustYNA MALISZEWSKA and EugENIA TĘGOWSKA
}

Department of Animal Toxicology, Faculty of Biology and Environment Protection, Nicolaus Copernicus University, ul. Lwowska 1, 87-100 Toruń, Poland; e-mails: ojustyna@umk.pl, tegowska@umk.pl

Key words. Blattodea, Blattidae, American cockroach, behavioural thermoregulation, capsaicin, capsazepine, TRPV

\begin{abstract}
Capsazepine is a competitive antagonist of capsaicin, a TRPV1 agonist responsible for the spicy taste of pepper. TRPV1 agonists and antagonists are known to affect mammalian body temperature, but their action on thermoregulation in insects is poorly known. In this study we evaluated the effect of capsazepine on the thermal preference of the American cockroach, Periplaneta americana using a thermal gradient. Our results revealed that capsazepine in submicromolar concentrations induces a preference for higher ambient temperatures when compared to the control insects. To assess whether capsazepine may act also as an antagonist of capsaicin in insects, we determined this insects' thermal behaviour when capsazepine was applied before capsaicin. The hypothermic response to capsaicin was clearly blocked by pre-treatment with capsazepine only in female American cockroaches. Our results indicate the involvement of structures functionally similar to TRPV1 in insect thermosensation.
\end{abstract}

\section{INTRODUCTION}

The main pungent alkaloid responsible for the spicy taste of pepper is capsaicin. It acts on the mammalian vanilloid receptor TRPV1 and induces a burning sensation (Caterina et al., 1997). The transient potential vanilloid receptor subtype 1 (TRPV1) is a member of a large group of the TRP family of receptors. Mammalian TRPV1 is a heat, ligand and proton-activated nonselective cation channel. This receptor is a nociceptor involved in body temperature regulation (Caterina, 2007). Some exogenous substances are known to affect organisms' thermoregulation via TRPV1. Capsaicin and other TRPV1 agonists induce a hypothermic response in mammals, while antagonists are known to induce a short hyperthermic effect (Gavva et al., 2007).

Capsazepine is a competitive antagonist of capsaicin (Bevan et al., 1992). It is the most extensively studied antagonist of the mammalian TRPV1 receptor, although characterized by limited selectivity (Jakab et al., 2005). For the heterologously expressed rat vanilliod receptor, capsazepine is less effective as a noxious heat response inhibitor than for heterologously expressed human TRPV1, and the response of rat TRPV1 to low $\mathrm{pH}$ is not blocked by capsazepine (McIntyre et al., 2001).

We previously demonstrated that capsaicin and capsazepine affect the behavioural thermoregulation of the mealworm, Tenebrio molitor. Larvae exposed to capsaicin at a low concentration $(0.1$ $\mu \mathrm{M}$ ) chose cooler ambient temperatures, whereas capsazepine at the same concentration induced a preference for a warmer environment relative to insects that were not treated. The similarity in the responses of insects and mammals indicates that capsaicin may influence structures that are at least functionally similar to mammalian TRPV1 (Olszewska \& Tęgowska, 2011). Similar results are reported by Zermoglio et al. (2015), which show that capsaicin induces preferences for lower temperatures in Rhodnius prolixus, while capsazepine treatment cause the opposite behaviour.

The aim of our study was to assess the effect of capsazepine (TRPV1 antagonist) on the thermal preference of the American cockroach, Periplaneta americana. American cockroach has TRP receptors. Wicher et al. (2005) screened the Periplaneta cDNA library for members of the TRPC family and found a homolog of the Drosophila TRPy channel. It is proposed that it is involved in forming the channel that conducts the $\mathrm{Ca}^{2+}$ background current in DUM neurons. Recently, French et al. (2015) demonstrated that the TRPL channel has a major role in Periplaneta phototransduction.

Based on our preliminary results we hypothesized that capsazepine influences thermoregulatory processes in insects. To confirm this hypothesis, we examined thermal preferences of cockroaches treated with five different capsazepine concentrations and released in a thermal gradient system. To establish whether capsazepine may act as a capsaicin antagonist in insects, we assessed the insect thermoregulatory response to capsaicin following pretreatment with capsazepine. We assumed that capsazepine blocks the insects' hypothermic response to capsaicin, as in mammals (Dogan et al., 2004).

\section{MATERIALS AND METHODS}

\section{Insects}

American cockroaches Periplaneta americana L. were reared in plastic containers at $\sim 26^{\circ} \mathrm{C}$ under a natural photoperiod. They were fed with oat flakes and apples and received drinking water at regular intervals. Only adult individuals were selected for the experiments. Experiments were performed separately on males 
and females. In each experimental series six individuals of both sexes were examined individually.

\section{Substances}

Capsazepine and capsaicin were obtained from Sigma Aldrich. Five different concentrations of capsazepine were tested: 0.01 ; $0.1 ; 1 ; 10$ and $100 \mu \mathrm{M}$. Based on the results only one concentration of capsazepine, $0.1 \mu \mathrm{M}$, was used in the further experiments. Capsaicin was tested at a $0.1 \mu \mathrm{M}$ concentration. To assess the effect of the combined treatment of insect with capsazepine and capsaicin, capsaicin was applied $90 \mathrm{~min}$ after capsazepine (as in Dogan et al., 2004). The capsaicin and capsazepine solvent - ethyl alcohol only (at the same concentration as in solutions of the tested substances $-1 \%$ ) was applied to one group of insects. Water was used in the control group of insects. In each experimental series, $10 \mu 1$ of the substances tested were placed on the mesothorax under the wings of the cockroaches. The substances were wiped away after $20 \mathrm{~s}$.

\section{Thermal preferences}

Thermal preferences of cockroaches were determined in a thermal gradient, which consisted of a long $(60 \mathrm{~cm})$ and narrow $(5$ $\mathrm{cm}$ ) trough. At one end the trough is heated by a thermostat (Fisherbrand ${ }^{\circledR}$ FBH 612; Fisher Scientific, Pittsburgh, USA) and at the other it is cooled down by a cryostat, thus creating a temperature gradient in the trough. The ambient temperature in this system ranged from $12^{\circ} \mathrm{C}$ to $40^{\circ} \mathrm{C}$. The thermal gradient system was divided into 20 compartments of equal length, and before each experiment the temperature in each compartment was measured with a thermocouple. Oat flakes and small containers with water were placed in different parts of the thermal gradient (water in: $19^{\circ} \mathrm{C}, 25^{\circ} \mathrm{C}, 32^{\circ} \mathrm{C}$; oat flakes in all compartments), so as not to affect the cockroaches distribution. Water was resupplied every $24 \mathrm{~h}$. Individual cockroaches were placed for $72 \mathrm{~h}$ in the thermal gradient (in the middle of the trough, $23.8 \pm 0.1^{\circ} \mathrm{C}$; always in the same direction) immediately after exposure to the substances tested. The behaviour of the insects in the thermal gradient was recorded using a camera (Sony HDR-XR 200VE) and saved on a computer disc. The images from the camera was recorded every three minutes using the BioVid program (FERRO Software, Bystra, Poland). All experiments were performed in 12-h cycles of light and dark.

\section{Data analysis}

The temperatures preferred by the insects were estimated from their positions recorded in the thermal gradient. All data was tested for normality (Kolmogorov-Smirnov test) and homogeneity of variance (Levene's test). A two-way ANOVA (factors: sex and capsazepine treatment) revealed that there is a significant difference in temperatures preferred by males and females after exposure to capsazepine $\left(\mathrm{F}_{1.6}=31.34, \mathrm{P}<0.001\right)$, so all analyses were performed separately for each sex. The effect of the substances tested on cockroaches' thermal preferences was assessed using a one-way ANOVA and a post hoc Tukey HSD test.

In addition, for each experimental series, the proportion of time spent in temperatures above $27^{\circ} \mathrm{C}$ (mean temperature preferred by control group) was estimated. Data was arcsine square-root transformed and compared using one-way ANOVA and a post hoc Tukey HSD test. The level of significance for all tests was 0.05 . All analyses were carried out using IBM SPSS Statistics 20 software. Data are presented as means \pm s.e.m.

\section{RESULTS}

\section{Capsazepine}

Insects that were not treated (control group) when placed into the thermal gradient system preferred $27^{\circ} \mathrm{C}\left(27.4^{\circ} \mathrm{C}\right.$ for males and

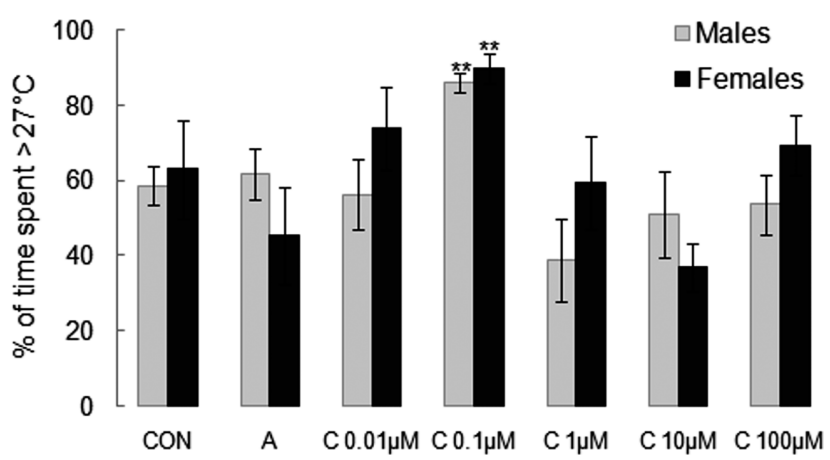

Fig 1. Percentage ( $\% \pm$ s.e.m.) of time Periplaneta americana males and females spent in temperatures above $27^{\circ} \mathrm{C}$ in the first $24 \mathrm{~h}$ after treatment with: water (CON), alcohol (A) and capsazepine $(C)$ applied in different concentrations $(n=6$ for each treatment). * indicates means significantly different from the control and alcohol treated groups (one-way ANOVA and post hoc Tukey test; ** $-\mathrm{P}<0.01)$.

$27.6^{\circ} \mathrm{C}$ for females; ANOVA: $\mathrm{F}_{1.10}=0.43, \mathrm{P}>0.05$ ). Based on this result, we determined the time spent by insects in the temperature gradient in areas with temperatures above $27^{\circ} \mathrm{C}$ in all experimental series (Fig. 1).

During the first $24 \mathrm{~h}$ the thermal preferences of American cockroaches were affected by the substances tested, both of females (ANOVA: $\mathrm{F}_{6.126}=51.629, \mathrm{P}<0.001$ ) and males (ANOVA: $\mathrm{F}_{6.126}$ $=9.813, \mathrm{P}<0.001$ ). However, application of alcohol (the capsazepine solvent) at the concentration used in the tests did not affect the temperatures preferred by cockroaches relative to the control group (post hoc Tukey test: $\mathrm{P}=0.07$ for females and $\mathrm{P}=0.56$ for males).

Insects treated with capsazepine at submicromolar concentrations $(0.01$ and $0.1 \mu \mathrm{M})$ chose higher ambient temperatures.

Females preferred $28.3 \pm 1.4^{\circ} \mathrm{C}(0.01 \mu \mathrm{M})$ and $30.4 \pm 0.6^{\circ} \mathrm{C}$ $(0.1 \mu \mathrm{M})$ in the first $24 \mathrm{~h}$ after treatment (post hoc Tukey test: $\mathrm{P}=$ 0.389 for $0.01 \mu \mathrm{M}$ capsazepine and $\mathrm{P}<0.001$ for $0.1 \mu \mathrm{M}$ capsazepine relative to the control group). These results were also significantly higher than for the group treated only with alcohol (post hoc Tukey test: $\mathrm{P}<0.001$ for $0.01 \mu \mathrm{M}$ capsazepine and $0.1 \mu \mathrm{M}$ capsazepine). When analyzing the percentage of the time spent at temperatures above $27^{\circ} \mathrm{C}$, females treated with $0.1 \mu \mathrm{M}$ capsazepine spent $89.8 \pm 3.9 \%$ of the time at temperatures above $27^{\circ} \mathrm{C}$ compared to $69.9 \pm 13.0 \%$ for the control group (ANOVA: $\mathrm{F}_{6.35}$ $=4.11, \mathrm{P}=0.003)$. This preference for remaining in the warmer parts of the thermal gradient persisted for $72 \mathrm{~h}$ (females spent $89.7 \pm 4.6 \%(0.01 \mu \mathrm{M}$ capsazepine $)$ and $96.4 \pm 0.8 \%(0.1 \mu \mathrm{M}$ capsazepine) of the time at temperatures above $27^{\circ} \mathrm{C}$ compared to $58.8 \pm 12.9 \%$ for the control group; ANOVA: $\mathrm{F}_{6.35}=5.39, \mathrm{P}=$ $0.001)$.

The males did not respond to capsazepine at the lowest concentration tested $(0.01 \mu \mathrm{M}$; post hoc Tukey test: $\mathrm{P}>0.05$ compared to the control and alcohol treated group). However, following the treatment with capsazepine at a concentration of $0.1 \mu \mathrm{M}$, males preferred temperatures that were higher than those preferred by the controls (post hoc Tukey test: $\mathrm{P}=0.02$ ) and the alcohol treated group (post hoc Tukey test: $\mathrm{P}<0.001$ ). When analyzing the percentage of the time spent above $27^{\circ} \mathrm{C}$ in the first $24 \mathrm{~h}$, males spent much more time at temperatures above $27^{\circ} \mathrm{C}(86.1 \pm 2.8 \%)$ than the control group $\left(58.6 \pm 5.3 \%\right.$ ) (ANOVA: $\left.\mathrm{F}_{6.35}=3.86, \mathrm{P}=0.005\right)$.

Capsazepine at higher concentrations $(1-100 \mu \mathrm{M})$ did not significantly change the thermal preferences of the treated cockroaches compared to the control group, except for capsazepine at a concentration of $1 \mu \mathrm{M}$, which induced a preference for cooler environments, in males (post hoc Tukey test: $\mathrm{P}=0.012$ ) and females (post hoc Tukey test: $\mathrm{P}<0.001$ ). 


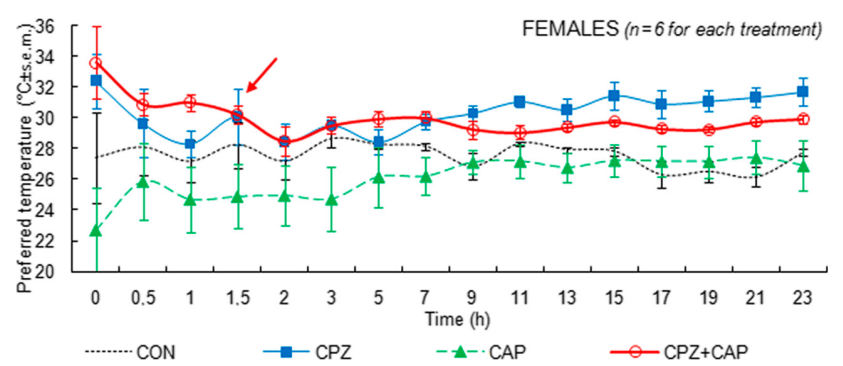

Fig 2. Temperature $\left({ }^{\circ} \mathrm{C}\right)$ preferred by Periplaneta americana females in the first $24 \mathrm{~h}$ after treatment with: water (CON), capsazepine (CPZ), capsaicin (CAP) and joint treatment with $0.1 \mu \mathrm{M}$ concentrations of capsazepine and capsaicin $(n=6$ for each treatment). The arrows indicate when the capsaicin was applied in the last experimental series (CPZ + CAP).

For males, the time spent at temperatures above $27^{\circ} \mathrm{C}$ was the shortest after treatment with $1 \mu \mathrm{M}$ capsazepine $(38.9 \pm 11.1 \%)$, whereas females spent the longest time in areas with temperatures lower than $27^{\circ} \mathrm{C}$ after treatment with $10 \mu \mathrm{M}$ capsazepine $(37.1 \pm$ $6 \%)$.

\section{Capsazepine pre-treatment}

To determine whether capsazepine acts as a capsaicin antagonist in insects, the effect of treatment with capsaicin on insects' thermal preferences after capsazepine pre-treatment was recorded. As shown in Fig. 2, after treatment with capsaicin American cockroach females remained in cooler parts of the thermal gradient for longer than the control group, and the mean temperature preferred in the first $24 \mathrm{~h}$ was $25.9 \pm 1.1^{\circ} \mathrm{C}$ (ANOVA: $\mathrm{F}_{4.99}=74.4$, $\mathrm{P}<0.001$, post hoc Tukey test: $\mathrm{P}<0.001)$. When capsazepine $(0.1$ $\mu \mathrm{M}$ ) was applied $90 \mathrm{~min}$ before capsaicin, there was no decrease in the preferred temperature following exposure to capsaicin. Females tend to remain for significantly longer at higher temperatures than after treatment with only capsaicin (ANOVA: $\mathrm{F}_{425}=$ 4.61, $\mathrm{P}<0.01$, post hoc Tukey test: $\mathrm{P}<0.01$ ), and at the same temperatures as recorded following the application of only capsazepine (post hoc Tukey test: $\mathrm{P}>0.05$ ). Sexes differed in their reaction to the substances tested. Periplaneta americana males treated with capsaicin after pre-treatment with capsazepine did not significantly change their thermal preferences compared to those insects treated with capsazepine and not treated (ANOVA: $\left.\mathrm{F}_{4.25}=1.20, \mathrm{P}>0.05\right)$. This reaction differed from that of the females of this species, which did not respond to capsaicin after pre-treatment with capsazepine. Moreover, males did not show as clear a hypothermic reaction after the application of only capsaicin as the females (Fig. 3).

\section{DISCUSSION}

Insect are poikilothermic animals, so temperature perception is essential for their survival. There are structures in insects that determine their thermosensation, which belong to the TRP family. Two TRPA subfamily members, Painless and Pyrexia, are needed for the detection of lethal temperatures $\left(>40^{\circ} \mathrm{C}\right.$ ) (Tracey et al., 2003; Lee et al., 2005). In Drosophila larvae another channel dTRPA1, is activated by temperatures of between 25 and $27^{\circ} \mathrm{C}$, which enables them to avoid temperatures above $30^{\circ} \mathrm{C}$ (Dillon et al., 2009). Different structures are involved in the sensing of cold by Drosophila. TRP and TRPL, members of the TRPC subfamily, which are involved in phototransduction, are essential for avoiding cold conditions (Rosenzweig et al., 2008). Gallio et al. (2011) report that a member of the TRPP subfamily, Brivido, are cold thermoreceptors in fruit flies, as brv mutants are poor at avoiding low temperatures. Interestingly, TRPA subfamily members are cold receptors in mammals and TRPV (vanilloid) a heat receptor.

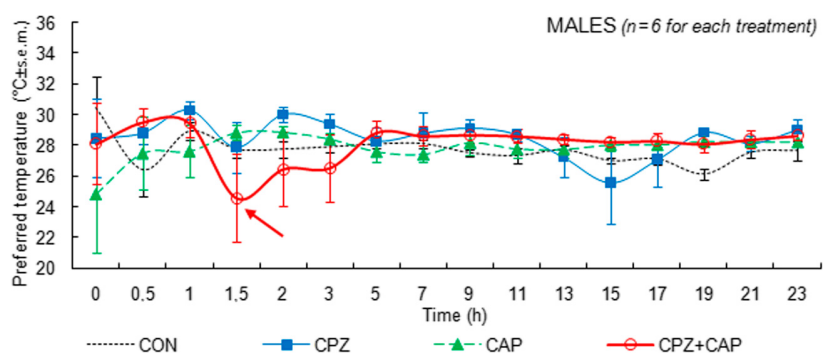

Fig 3. Temperature $\left({ }^{\circ} \mathrm{C}\right)$ preferred by Periplaneta americana males in the first $24 \mathrm{~h}$ after treatment with: water (CON), capsazepine (CPZ), capsaicin (CAP) and joint treatment with $0.1 \mu \mathrm{M}$ concentrations of capsazepine and capsaicin ( $n=6$ for each treatment). The arrows indicates when capsaicin was applied in the last experimental series (CPZ + CAP)

In Drosophila, two members of the TRPV subfamily are known: Nanchung and Inactive. Both receptors are located in the antennal chordotonal organ and form a complex essential for hearing (Gong et al., 2004). However, both Inactive and Nanchung CHOexpressing cells are unresponsive to capsaicin and temperature (Kim et al., 2003; Gong et al., 2004). Yet, this does not exclude a possible role of TRPV channels in insect thermosensation. Sokabe et al. (2008) demonstrated that in vivo and in vitro results may differ. In vivo, flies showed an aversion to food containing allyl isothiocyanate, a mustard ingredient, which is mediated by the Painless receptor (painless mutants do not show an aversive behaviour) and mammalian TRPA1. However, Painless expressed in HEK293 cells did not respond to this substance. Furthermore, Kwon et al. (2010) show that Inactive is important for insect thermoreception.

In a previous study we found that like mammals mealworms respond to TRPV1 agonists and antagonists (Olszewska \& Tęgowska, 2011). In the current research, we evaluated the effect of a TRPV1 antagonist, capsazepine, on thermal preferences of the American cockroach. The results indicate that treatment with capsazepine in submicromolar concentrations $(0.1 \mu \mathrm{M}$ especially) induce a preference for higher ambient temperatures in insects.

In mammals, TRPV1 antagonists are known to not only block hypothermia induced by treatment with capsaicin, but also cause hyperthermia (Gavva et al., 2007). Capsazepine blocks the capsaicin-induced hypothermic response in rats, but it does not cause hyperthermia (Dogan et al., 2004). It is thought that hyperthermia only occurs when an antagonist blocks both capsaicin and proton activation, and in rats, capsazepine does not inhibit activation of TRPV1 by low $\mathrm{pH}$, although it blocks proton activation in guinea pigs (Romanovsky et al., 2009). Our results revealed that the American cockroach shows a hyperthermic response to submicromolar concentrations of capsazepine. This implies that capsazepine may act on structures that are at least functionally similar to mammalian TRPV1.

To determine whether capsazepine is an antagonist of capsaicin in insects, we assessed the effect of pre-treatment with capsazepine 90 min before the application of capsaicin. In mammals capsazepine suppress the hypothermic response induced by capsaicin (Dogan et al., 2004). Our results indicate that capsazepine has the same effect in insects. Periplaneta americana females treated with capsaicin seek the cooler parts of the thermal gradient, while after pre-treatment with capsazepine the application of capsaicin had no effect. These results confirm that capsazepine is also an antagonist of capsaicin in insects.

The differences in female and male responses to capsaicin and capsazepine are very interesting. The response of males to cap- 
saicin is weaker than that of females, whereas after pre-treatment with capsazepine their reaction to capsaicin was stronger than that of females. It is difficult to explain this phenomenon as there is very little data in the literature. Females of pygmy grasshoppers prefer significantly higher ambient temperatures than males (Forsman, 2000). He also records a significant variation in preferred body temperatures between individuals of different colour morphs of females, but not males. He explains this difference between the sexes in terms of the strong temperature effect on the reproductive performance in this grasshopper species.

Some aspects of life history may account for the differences in the behaviour of the different sexes of cockroaches. Seelinger (1984) describes sex-specific differences in the spatial distribution of Periplaneta americana. Males usually leave their shelters in the evening, move to exposed sites and return to the same shelters night after night. Virgin females regularly visit exposed sites and spend several hours there calling, while mated females leave their shelters only for short periods for feeding. These differences in cockroach behaviour may reflect different responses to external factors, such as capsaicin.

Periplaneta sexes differ also in their response to toxicants. When immunized with honeybee venom, females show a more enhanced and prolonged immunological response compared to males (McCllelan-Green et al., 2007). Differences in the reaction of sexes to treatment may result from differences in uptake, metabolism and elimination of a toxicant. The females of Periplaneta americana are bulkier than the males (Bell et al., 2007). Capsaicin and capsazepine dissolve in lipids, so a larger amount of these substances may spread and affect tissues.

It is suggested that TRPV1 sensitivity to capsaicin is an evolutionary acquisition in mammals, as zebrafish, amphibian and avian TRPV1 are residually sensitive to this substance (Jordt \& Julius, 2002; Ohkita et al., 2012; Gau et al., 2013). Although insect vanilloid receptors (Nanchung and Inactive) do not respond to capsaicin, this alkaloid is reported to repel some species of insects, for example, Sitophilus zeamais (Spurr \& McGregor, 2003). However, this does not imply that insects have receptors sensitive to capsaicin.

The target of capsaicin at low concentrations in cockroaches may not be similar to the TRPV channel. Al-Anzi et al. (2006) show that wild-type flies show a positive preference for capsaicin in food preference tests. The authors suggests that the ability to detect capsaicin is unlikely to be mediated by direct binding to a TRP channel, but more likely that it involves the activation of a gustatory receptor.

It cannot be excluded that the results reflect other, non-specific capsazepine effects in insects. Capsazepine at a concentration $\geq 1$ $\mu \mathrm{M}$ acts in a non-specific manner in rat dorsal root ganglion neurons by blocking voltage-activated calcium currents. However, $\mathrm{IC}_{50}$ for a blocking response induced by capsaicin is lower: $0.1-$ $0.7 \mu \mathrm{M}$ (Docherty et al., 1997). We recorded inhibiting effect of capsazepine on $0.1 \mu \mathrm{M}$ capsaicin.

In the presented experiments, capsazepine at higher concentrations $(1 \mu \mathrm{M})$ induced preference for lower ambient temperatures than recorded for non treated insects. This is consistent with Lundbæk et al's (2005) results, which show that at micro- to milimolar concentrations both capsaicin and capsazepine act in a similar way on many membrane proteins by inducing changes in membrane fluidity. Capsazepine and capsaicin adsorb on lipid bilayers and modify bilayer physical properties. These changes are sufficient to change the conformation of membrane proteins, and, for example, to inactivate voltage-gated $\mathrm{Na}^{+}$channels. At micro- to milimolar concentrations, capsazepine non-specifically affects many membrane proteins by altering bilayer elasticity, and this may affect insects' thermal preferences in various ways.
However, it can be speculated that when the lipid bilayer fluidity increases, insects would choose cooler environments to restore regular stiffness of the membrane.

We recorded two types of reaction in our experiments - insects' preference for higher temperatures after application of capsazepine at submicromolar concentrations, and for slightly lower ambient temperatures when treated with micro- to milimolar concentrations. Moreover, capsazepine acted as a capsaicin antagonist in American cockroach females. These results indicate the involvement of structures, which are at least functionally similar to TRPV1, in the thermosensation of cockroaches.

ACKNOWLEDGEMENTS. This study was supported by Nicolaus Copernicus University [grant number 1531B].

\section{REFERENCES}

Al-Anzi B., Tracey W.D. JR \& Benzer S. 2006: Response of Drosophila to wasabi is mediated by painless, the fly homolog of mammalian TRPA1/ANTKM. - Curr. Biol. 16: 1034-1040.

Bell W.J., Roth L.M. \& Nalepa C.A. 2007: Cockroaches: Ecology, Behavior, and Natural History. The Johns Hopkins University Press, Baltimore, $230 \mathrm{pp}$.

Bevan S., Hothi S., Hughes G., James I.F., Rang H.P., Shah K., Walpole C.S.J. \& Yeats J.C. 1992: Capsazepine: a competitive antagonist of the sensory neurone excitant capsaicin. $-B r$. J. Pharmacol. 107: 544-552.

CATERINA M.J. 2007: Transient receptor potential ion channels as participants in thermosensation and thermoregulation. - Am. J. Physiol. Regul. Integr. Comp. Physiol. 292: 64-76.

Caterina M.J., Schumacher M.A., Tominaga M., Rosen T.A., LeVINE J.D. \& Julius D. 1997: The capsaicin receptor: a heatactivated ion channel in the pain pathway. - Nature 389: 816-824.

Dillon M.E., Wang G., Garrity P.A. \& Huey R.B. 2009: Review: thermal preference in Drosophila. - J. Therm. Biol. 34: 109-119.

Docherty R.J., Yeats J.C. \& Piper A.S. 1997: Capsazepine block of voltage-activated calcium channels in adult rat dorsal root ganglion neurones in culture. - Br. J. Pharmacol. 121: 14611467.

Dogan M.D., Patel S., Rudaya A.Y., Steiner A.A., Székely M. \& Romanovsky A.A. 2004: Lipopolysaccharide fever is initiated via a capsaicin-sensitive mechanism independent of the subtype-1 vanilloid receptor. - Br. J. Pharmacol. 143: $1023-$ 1032.

FORSMAN A. 2000: Some like it hot: intra-population variation in behavioral thermoregulation in color-polymorphic pygmy grasshoppers. - Evol. Ecol. 14: 25-38.

French A.S., Meisner S., Liu H., Weckström M. \& TorkKeli P.H. 2015: Transcriptome analysis and RNA interference of cockroach phototransduction indicate three opsins and suggest a major role for TRPL channels. - Front. Physiol. 6: 207.

Gallio M., Ofstad T.A., Macpherson L.J., Wang J.W. \& Zuker C.S. 2011: The coding of temperature in the Drosophila brain. - Cell 144: 614-624.

Gau P., Poon J., Ufret-Vincenty C., Snelson C.D., Gordon S.E., Raible D.W. \& DhaKa A. 2013: The zebrafish ortholog of TRPV1 is required for heat-induced locomotion. - J. Neurosci. 33: 5249-5260.

Gavva N.R., Bannon A.W., Surapaneni S., Hovland D.N., Lehto S.G., Gore A., Juan T., Deng H., Han B., Klionsky L., Kuang R., Le A., Tamir R., Wang J., Youngblood B., Zhu D., Norman M.H., Magal E., Treanor J.J. \& Louis J.C. 2007: The vanilloid receptor TRPV1 is tonically activated in vivo and involved in body temperature regulation. - J. Neurosci. 27: 3366-3374. 
Gong Z., Son W., Chung Y.D., Kim J., Shin D.W., McClung C.A., Lee Y., Lee H., Chung D.J., KaAng B.K., Cho H., OH U., Hirsh J., Kernan M.J. \& KIm C. 2004: Two interdependent TRPV channel subunits, inactive and Nanchung, mediate hearing in Drosophila. - J. Neurosci. 24: 9059-9066.

JoRDT S.E. \& Julius D. 2000: Molecular basis for species-species sensitivity to "hot" chili peppers. - Cell 108: 421-430.

Kim J., Chung Y.D., Park D., Chol S., Shin D.W., Soh H., Lee H.W., Son W., Yim J., Park C.S., Kernan M.J. \& Kim C. 2003: A TRPV family ion channel required for hearing in Drosophila. - Nature 424: 81-84.

Kwon Y., Shen W.L., Shim H.S. \& Montell C. 2010. Fine thermotactic discrimination between the optimal and slightly cooler temperatures via a TRPV channel in chordotonal neurons. - J. Neurosci. 30: 10465-10471.

Lee Y., Lee Y., Lee J., Bang S., Hyun S., Kang J., Hong S.T., Bae E., KaAng B.K. \& Kim J. 2005: Pyrexia is a new thermal transient receptor potential channel endowing tolerance to high temperatures in Drosophila melanogaster. - Nature Gen. 37: $305-310$

Lundbek J.A., Birn P., Tape S.E., ToOmbes G.E.S., SøgaArd R., Koeppe II R.E., Gruner S.M., Hansen A.J. \& Andersen O.S. 2005: Capsaicin regulates voltage-dependent sodium channels by altering lipid bilayer elasticity. - Mol. Pharmacol. 68: 680-689.

McCllelan-Green P., Romano J. \& Oberdörster E. 2007: Does gender really matter in contaminant exposure? A case study using invertebrate models. - Environ. Res. 104: 183-191.

McIntyre P., McLatchie L.M., Chambers A., Phillips E., Clarke M., Savidge J., Toms C., Paecock M., Shah K., Winter J., Weerasakera N., Webb N., Rang H.P., Bevan S. \& James I.F. 2001: Pharmacological differences between the human and rat vanilloid receptor 1 (VR1). — Br. J. Pharmacol. 132: 1084 1094.

Ohkita M., Saito S., Imigawa T., Takahashi K., Tominaga M. \& ОнтА T. 2012: Molecular cloning and functional characterization of Xenopus tropicalis frog transient receptor potential va- nilloid 1 reveal its functional evolution for heat, acid, and capsaicin sensitivities in terrestrial vertebrates. - J. Biol. Chem. 287: 2388-2397.

OlszewsKa J. \& TĘGOWSKa E. 2011: Opposite effect of capsaicin and capsazepine on behavioral thermoregulation in insects. J. Comp. Physiol. (A) 197: 1021-1026.

Romanovsky A.A., Almeida M.C., Garami A., Steiner A.A., Norman M.H., Morrison S.F., NaKamura K., Burmeister J.J. $\&$ NuCCI T.B. 2009: The transient receptor potential vanilloid-1 channel in thermoregulation: a thermosensor it is not. - Pharmacol. Rev. 61: 228-261.

Rosenzweig M., Kang K. \& Garrity P.A. 2008: Distinct TRP channels are required for warm and cool avoidance in Drosophila melanogaster. - Proc. Natl. Acad. Sci. U.S.A. 105: 14668-14673.

Seelinger G. 1984: Sex-specific activity patterns in Periplaneta americana and their relation to mate-finding. $-Z$. Tierpsychol. 65: 309-326.

Sokabe T., Tsujiuchi S., Kadowaki T. \& Tominaga M. 2008: Drosophila painless is a $\mathrm{Ca}^{2+}$-requiring channel activated by noxious heat. - J. Neurosci. 28: 9929-9938.

SpurR E.B. \& McGregor P.G. 2003: Potential invertebrate antifeedants for toxic baits used for vertebrate pest control. - Sci. Conserv. 232: 13 .

Tracey D.W. JR, Wilson R.I., Laurent G. \& Benzer S. 2003: painless, a Drosophila gene essential for nociception. - Cell 113: 261-273.

Wicher D., Agricola H.J., Schöner R., Heinemann S.H. \& Derst C. 2006: TRP $\gamma$ channels are inhibited by cAMP and contribute to pacemaking in neurosecretory insect neurons. - J. Biol. Chem. 281: 322-326.

Zermoglio P.F., Latorre-Estivalis J.M., Crespo J.E., Lorenzo M.G. \& LAZZARI C.R. 2015: Thermosensation and TRPV channel in Rhodnius prolixus. - J. Insect Physiol. 81: 145-156.

Received February 1, 2016; revised and accepted March 14, 2016 Published online April 21, 2016 